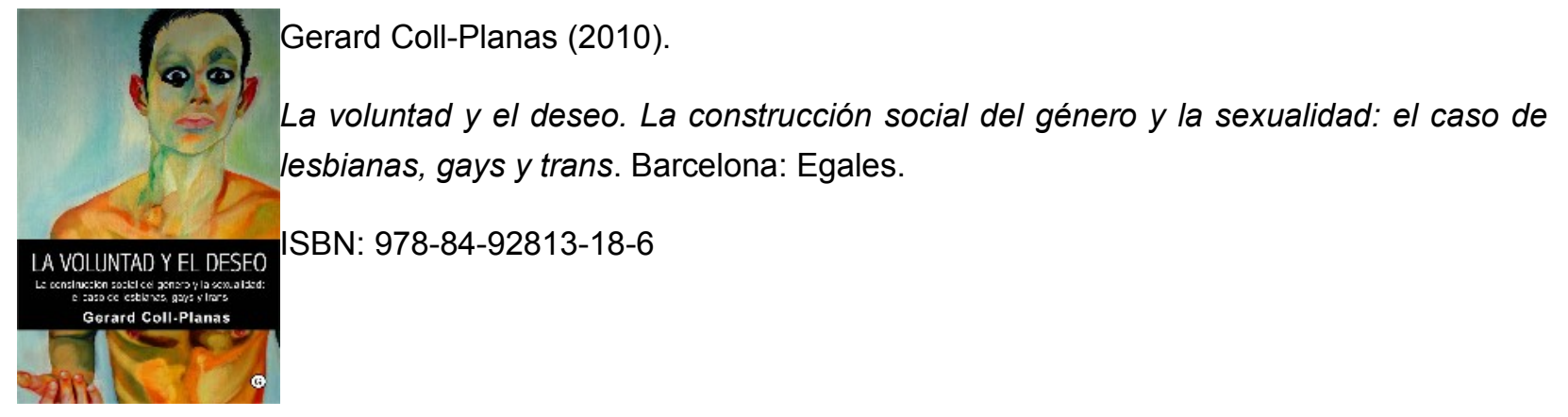

Brígida Maestres Universitat Autònoma de Barcelona

bmaestres@uoc.edu

Una vez vi cómo se derramaba brea de un barril hasta impregnar a un gallo. Vi cómo las plumas de ese animal se transformaban en viscosidad. Vi entonces cómo su negra silueta se subía al barril para dejarse caer dentro. Se diría que la necesitaba... Nunca más vi ni al gallo ni a la brea; en adelante sólo conseguí ver movimientos casi pétreos, que a veces parecían cuerpos.

Festejar con alegría los descubrimientos, no es sólo cuestión de naturalistas. La lectura de este texto nos permite a las ciencias sociales, celebrar el encuentro con el principio fundante y con el mecanismo defensivo de nuestro orden segmentario: la transexualidad; la fobia a... Se trata de la crónica del padecimiento del límite. La agonía que nos proponen las matemáticas, que siendo infinita la distancia entre dos puntos, jamás nunca el límite podrá ser alcanzado, es el mismo padecimiento crónico del "ideal de yo", que traducido a órdenes segmentarios -que pensamos cómo no nuestros-, nos sitúa al amparo de un mandato de género con sus ideales correspondientes, con sus mecanismos de ordenamiento, con sus dispositivos de vigilancia. Sexo: mujer; rol: femenino; preferencias: hombres.

No es cuestión de desvirtuar las luchas específicas que nos plantea el libro, si enunciamos su descubrimiento en este postulado más generalista: aquello que delimita nuestra expresión de la sexualidad, es el contorno de la transfobia. Su expresión tiene lugar en ese arreglo monolítico de sexualidades complementarias, y de roles en consonancia perfecta con ese ideal. Una condición del ser y para el ser, emanadas desde las partes más púdicas de un cuerpo sexuado en términos binarios, por la gracia de una palabra ya introyectada como "deber ser" en los tiempos modernos. La agonía, múltiples posibilidades en la resolución del conflicto edípico y múltiples posibilidades de cuerpos sexuados, malgastadas en sus combinatorias de deseo e identidades posibles, en razón de un mandato de combinatoria unívoca. Un edipo positivo, un deseo heterosexual, un yo reconciliado con el contenido de su referente "par".

El libro nos hace ocuparnos del episodio de marginación de gays, lesbianas y transexuales a causa de este orden transfóbico de segmentación. En éste, sin embargo, otros episodios son posibles: todo aquello que haga desencajar o desencaje al sexo biológico de su rol social atribuido; todo lo que haga 
desencajar la taxonomía de "macho y hembra" del saber hegemónico sobre cuerpos sexuados. He aquí, entonces, la algarabía de esta celebración: en tanto milimétricas y cada vez más visibles, nos descubrimos siempre en calidad de protagonistas de esta vulneración, mientras nos sujetamos al mandato como única posibilidad de cobrar existencia. Lo que celebramos es, entonces, ya no sabernos en la realidad de las cosas sino en delimitados en nuestra experiencia por los contornos de una caverna, con múltiples recorridos de entradas y salidas. Todo lo que se puede objetivar, deviene entonces fuente para la disección, como el género.

Lo de episodio no es mera retórica de esta reseña. La hipótesis fundamental de Gerard Coll-Planas en este libro nos advierte: que cuando fue necesario consolidar un mandato de género al que se subordina un mandato de sexualidad, era el momento de la construcción de este ideal, de su sacralización al engullirse cualquier posibilidad del ser para escupirla como patología. Pero ahora, que ya la sexualidad se sobreentiende cómo arraigada y normalizada a sus mandatos de género, sus grandes amenazas en la historia reciente han sido episódicas dentro de un largo recorrido de re-incorporación de lo otrora patologizado en el espacio de lo humano. Las luchas de mujeres, el tránsito de la exclusión a sólo la marginación de gays y lesbianas. El momento es, entonces, el que ahora profiere la transexualidad, que en tanto su creciente visibilidad socava -en tanto exterior constitutivo- los cimientos de una sexualidad que se resiste a su propio desorden. Se le patologiza como práctica habitual de defensa en contra de la amenaza. Se le deshumaniza, se le interviene quirúrgicamente. Se le excluye. No obstante, como el episodio es también el de una lucha, se trata del encuentro de un orden con su desorden constitutivo. Al observársele como fobia, ya se le puede intervenir en el punto ciego de su episteme.

El libro no se trata, sin embargo, de un compendio de lemas para lucha, o de incentivos para tranquilizar la culpa por el deseo individual. Cuando hablamos de un descubrimiento, debemos advertir el contenido de este libro cómo un cúmulo estructurado de premisas epistémicos, debates teóricos y referentes empíricos, que nos aseguran la rigurosidad del artefacto. Un importante debate sobre el "cómo conocer", que sitúa la legitimidad del conocimiento en la experiencia de un sujeto constituido, como síntesis por coordenadas socio históricas. Un debate entre construccionistas y psicoanalistas, que nos permite llenar los vacíos teóricos de ambas, tanto al descubrir el carácter socio histórico de la pulsión sexual, como abrir el camino a la comprensión sociológica del padecimiento individual de un sujeto que introyecta pautas individualmente. En su síntesis, el postulado de un sujeto paradójico, que sólo se constituye de un poder que, sin embargo, subvierte.

No obstante, se trata de un encuentro con el límite, que da agencia al sujeto para esta subversión al desposeerlo de saberes y discursos deterministas, pero que le advierte que las posibilidades de su subversión no dependen tan sólo de la voluntad. No son infinitas, y en su recorrido, un principio de responsabilidad con, y ante, la realidad es preciso. Aquí, la tensión entre la voluntad de cambio, y el deseo que reivindica su humanidad, se relimitan ya no en atención al binomio normal y patológico, sino ante el límite de la propia capacidad dentro de este nuevo dispositivo de libertad legítima que nos propone el libro. Desde este límite, el goce o la anomia que engendra un deseo y una identidad dispar, no reconocida, se transforma en deseos constituidos e identidades posibles, legitimadas, comprensibles, que nos invitan a hipotetizar sobre el carácter perenne y renovable del complejo de Edipo, y sobre cómo ha de proferirse la inclusión de sus resoluciones en una escena de lo humano. La brea, aunque permanece como metáfora social, posibilita siempre el movimiento y la delimitación de nuevos cuerpos. He aquí, entonces, la responsabilidad que nos propone el límite de la alteridad, no obstante, la posibilidad de la inclusión en la escena legítima de todos los contornos de cuerpos posibles. Veamos... 


\section{Formato de citación}

Maestres, Brígida (2010). Reseña de Coll (2010) La voluntad y el deseo. Athenea Digital, 19, 231-233.

Disponible en

http://psicologiasocial.uab.es/athenea/index.php/atheneaDigital/article/view/401/788.

Este texto está protegido por una licencia Creative Commons.
Usted es libre de copiar, distribuir y comunicar públicamente la obra bajo las siguientes condiciones:
Reconocimiento: Debe reconocer y citar al autor original.
No comercial. No puede utilizar esta obra para fines comerciales.
Sin obras derivadas. No se puede alterar, transformar, o generar una obra derivada a partir de esta obra.
Resumen de licencia - Texto completo de la licencia

